\title{
TEN YEARS AFTER THE CRISIS IN HUNGARY
}

\author{
György SURÁNYI
}

Looking back to the global financial crisis of 2008-2009, Hungary was among the first countries to be forced to make use of financial assistance from the EU and the IMF. The government, the MNB (the central bank of Hungary) as well as the domestic and foreign analysts cited the high public debt and the volume of unsecured foreign-currency loans as the main reasons for the crises. Though these were real weaknesses, this diagnosis was false as much as the following treatment. First and foremost, it was the inadequate level of foreign exchange reserves that made Hungary to request outside financial assistance.

The excessive fiscal tightening urged by the MNB only led to deepening of the crises. In general, the macropolicy - both fiscal and monetary policy - before, during and after the crises turned out to be painfully pro-cyclical. Due to the lack of sufficient reserves, the MNB became virtually powerless to intervene and could only watch from the side-lines as events unfolded. The orthodox mind-set after replenishing the forex reserves prevented it from implementing a broad scale of unconventional measures to ease the crises. The fiscal authority lost its capacity long before to reduce the severity of the crises. Thus, the excessive and incorrect structure of fiscal correction coupled with an unjustified orthodox monetary policy, the contraction of the Hungarian economy went much beyond the inevitable amount.

Keywords: monetary policy, fiscal and monetary policy mix, external debt, reserve management, unconventional monetary policy, orthodox monetary policy, foreign exchange liberalization, procyclical macroeconomic policy, Hungary

JEL classification indices: G01, G15, G17, G18, G20, G28, H 63

György Surányi, Professor of Finance, Former Governor of the central bank of Hungary (MNB) 1990-1991, 1995-2001. E-mail: gyorgysuranyi@gmail.com 


\section{INTRODUCTION}

A decade has passed since the breakout of the Great Recession, the financial and economic crisis that shook the world. ${ }^{1}$ It is a good indication of the severity of the crisis that economic growth has not returned to the level that existed before the crisis to date. This also means that growth in the global economy and in individual countries remains well below earlier trends. What is more depressing than this is that the external and internal financial imbalances experienced at the time when the crisis surfaced continue to exist, albeit not with the same structure and intensity and not the same way for each country. Furthermore, the income inequality in developed, developing and emerging economies, which were perhaps the most important drivers underpinning the occurrence of the crisis, have continued to increase. This took place in spite of the fact that the deepest crisis to occur since the Great Depression was handled pragmatically, using a broad range of non-conventional instruments, primarily in the Anglo-Saxon world and later on, on a lesser scale, in Europe as well. One might say that the exercise was not without success, although the clouds of storm are far from having passed due to the reasons mentioned above. Moreover, the means available for handling a crisis to come and the room for economic manoeuvring have shrunk perceptibly.

The 10-year anniversary offers an opportunity for taking a look back and reconsidering events through an analysis of how the crisis has unfolded and progressed in Hungary. Following the collapse of Lehman that closed the evolution phase of the global economic crisis and escalated it to a dramatic scale without exaggeration, Hungary was among the first to be forced to make use of the financial assistance, that is, the loans (and not aids) from the IMF and the European Union. Many have asked the question since then, and not without reason: why did we have to be among the first to come under the "care" of international organisations pursuant to the external shock of the global economy that affected a multitude of countries as well as our own region? It is worthwhile to recall and analyse the processes of the periods that preceded and followed the crisis. The question cannot be answered without touching upon the backdrop of the crisis and the orthodox liberal (mainstream) approach to economic policy that was dominant worldwide and in Hungary at that time. This is not merely because the customary analyses often rely on no more than half-truths and political bias, but mostly because one cannot build robust crisis management on half-truths, whether now or in the future.

1 This paper is an updated and revised version of an analysis entitled „Téves diagnózis, téves terápia (Misdiagnosis, Mistherapy)”, published in Népszabadság, January 30, 2010. 
Our Hungarian story began well before 2008. After the near-crisis in 1995, the Hungarian economy adopted an undoubtedly sustainable growth path that preserved equilibrium and became the fastest growth track in the Central European region. The adjustment program was a kind of shock therapy, but the nature of it was heterodox. Growth was driven by exports and investment, facilitated by a considerable amount of foreign capital inflow. In 2001, however, there was a change in the paradigm of economic policy. Growth driven by exports and investments was replaced by a policy based on excessive budget expenditure and consumption. This turnaround put the Hungarian economy onto an unsustainable growth path, years before the economic crisis. As a result of the combination of loose fiscal and income policy, and the monetary policy that was intended to be strict to counterbalance it gradually undermined its sustainability. It has become increasingly obvious that the external and internal financial balance have come to a dangerous stage close to collapse by the summer of 2006. The fiscal policy characterised by a high deficit, which was $7-8 \%$ of GDP on average, the high and rising fiscal redistribution (from 42\% of GDP in 2001 to 50\%), and the increase in real wages that reached double the rate of productivity on average and lasted for nearly five years were all consciously intended to boost demand, and thus, to spur growth. This was done in a situation when the impetus of economic growth was there, and no traces of a lack of demand could be spotted.

The fiscal expansion on the one hand and the unrealistically quick rise in real wages on the other hand resulted in overheating the economy, which brought down the balance between investments and savings permanently and significantly. The permanent excess demand caused an increasingly constant inflationary pressure concurrently with significant external imbalances. The current account deficit hiked from $4-5 \%$ to $8 \%$ of GDP, and a shrinking portion of this was financed by non-debt type items. With reference to this, monetary policy opted for an unreasonably high HUF base rate throughout the entire period in a contradictory manner. By doing so, on the one hand it inadvertently contributed to the rise in domestic (foreign currency denominated loan - FX hereafter) demand due to the widening interest rate differential. On the other hand, it reigned in growth and had an adverse impact on external balance by fostering the artificial appreciation of the nominal and real exchange rate.

\section{THE PRICE OF LACK OF HARMONY}

By the summer of 2006, the Hungarian economy that grew sustainably fast between 1997 and 2001 at an annual rate of 4-5\% tipped over towards external and internal financial imbalance, while the growth rate dropped back to 3-4\%. On 
the one hand, in line with the intentions of fiscal policy (but without being aware of it), a strongly pro-cyclical policy was pursued. On the other hand, in contrast with its intentions, the monetary authority implemented a pro-cyclical policy as well that increased demand and, ultimately, inflation. As a net result of the procyclical fiscal and monetary policies which mutually strengthened each other, the external and internal balances were undermined, nearly fatally. This was in spite of the fact that the otherwise (excessively) favourable environment in the international money and capital markets financed the external imbalance apparently easily and nearly automatically. The National Bank of Hungary (with Hungarian abbreviation: MNB) drew the mistaken conclusion from this that the external limit on financing ceased to exist and was irrelevant. This was no different from the dogma prevailing in the EMU at that time too. The fact that this concept was not sustainable in general and more specifically even in the Eurozone had to be realised in the course of the euro crisis that unfolded after 2010. Nevertheless, making a macroeconomic adjustment became inevitably urgent in the summer of 2006.

The programme elaborated and commenced after the 2006 elections was painful and not merely in itself. Acceptance of this programme and adapting to it was incredibly more difficult than customary in similar cases for all. In the light of the efficient obscurantism, the conscious misleading of the public, the ongoing self-deception that have been going on in preceding years, and the unfounded promises that could be heard from every source for the elections undoubtedly lent a disillusioning air to the adjustments/austerity measures.

The EU-required convergence programme was implemented amidst considerable opposition underpinned by a deep credibility gap in a debatable structure and without sufficient professional preparation. At the same time, after lengthy delays and partly justified by these delays, the programme aimed at fiscal adjustments on an unprecedented scale. In the course of two and a half years, it suppressed budget deficit from a level exceeding $11 \%$ of GDP to between $3 \%$ and $4 \%$ of GDP. (The reduction of the deficit was even more dramatic considering that the rate of inflation was between $6 \%$ and $8 \%$ p.a., meaning the operational deficit was reduced even more.) While the structure of the adjustment may be debatable, another of its features - in addition to the quantitative adjustment - nevertheless deserves attention. After long years, not only were the six-monthly and annual balances of the budget harmonised with the programme announced and approved by the Parliament, but also public finances were closed with a deficit visibly lower than the approved target every year.

Ever since then, there have been numerous references to the unfavourable structure of fiscal adjustments, among them by the representatives of the central bank. As indicated earlier, I could also have envisaged a better structure, yet I 
do not share much of the criticism. Firstly, an adjustment of this scale and pace cannot be made only on the expenditure side. Secondly, the larger part of the adjustments, some $60 \%$ of them - contrary to the popular belief - concerned expenditure. Thirdly, it is an illusion to believe that intervention on the expenditure side is necessarily anti-inflationary, growth-friendly, or significantly less painful than austerity on the revenue side. Fourth, sometimes it is not easy to decide in which side of the budget a particular step affects more, such as tuition fees which may reduce expenditure or raise revenue.

Since the fiscal policy was not any more unpredictable and irrational, therefore, one of the fundamental factors that made it nearly impossible to harmonise the fiscal and monetary policy ceased to exist. However, this offers no reason to celebrate, as this would be the starting point in a normal world.

Yet, in the light of the events leading up to that point this was perhaps the most important change in the substance of the government's policy. A favourable change beyond quantitative fiscal adjustment, if any, was undoubtedly the strengthening of fiscal discipline, which brought about greater predictability and a reduction in the lack of confidence.

In spite of the quick and brutal fiscal adjustment which well exceeded the approved target, opinions on the Hungarian economy failed to improve or improved only to a minor extent. In addition to the loss of confidence in policies and actors, the fact that growth has lost considerable speed as a short-term side effect of the adjustment is likely to have played a dominant role in this. In the light of the robust growth of neighbouring countries, which was often not sustainable there, the Hungarian economy's growth rate of $1 \%$ to $2 \%$ p.a. was found to be outstandingly weak. Due to the unfavourable structure of the adjustment, this sluggish growth rate was accompanied by an unsustainable need for external financing of as much as $8 \%$ to $9 \%$ of GDP annually and pursuant to that external indebtedness that appeared to be unstoppable.

How is it possible that such a deep fiscal adjustment - which was at least twice the size of the adjustment carried out in 1995 when cleared of inflationary effects, and which addressed the twin deficit so efficiently back then - failed to be reflected in the external imbalance?

The economic policy mix applied in 2006 was fundamentally different from that of 1995. The fiscal, income and monetary policies relying on mutual trust, which were comprehensively harmonised, represented the pillar of stabilisation in 1995. The stringent fiscal and income policies, and the reasonably strict monetary policy (thought to be merely accommodative by some analysts) efficiently restricted domestic demand primarily for consumption purposes, inevitably reduced real income, while preserving the most important achievement, being the level of employment. On the other hand, it consciously supported the export sec- 
tor and private investment. As a result of these two impacts, restraining domestic consumer demand and facilitating export and investments have brought about a spectacular improvement in external balance, avoided recession, and accelerated short term growth.

In contrast, the economic policy mix of the adjustment after 2006 and the co-operation of fiscal and monetary policies continued to be characterised by mutual mistrust and a lack of coordination. The strict and, finally, predictable fiscal policy were coupled with a monetary policy that was unreasonably but at least contradictorily and selectively strict. In quantitative terms, the fiscal and income policy adjustments were appropriate, bringing about painful restrictions on domestic consumer demand. At the same time, the structure of this austerity measure had an explicitly detrimental impact on the business sector and growth prospects. It did not have a single element to substantially improve the business environment and competitiveness; to the contrary, it made things worse in this respect, while contributing to an increase in unemployment and slowing down the medium-term growth potential of the economy. In addition, this fiscal policy remained pro-cyclical, but with a reverse sign compared to the earlier period.

The fiscal policy that was predictable in quantitative terms and could be foreseen to curb demand was coupled with an apparently very strict comprehensive monetary policy that intended to also restrict domestic demand. However, as time passed since September 2006, the central bank, which had no trust in the implementation of the fiscal adjustment,continued to restrict measurable monetary conditions more than was necessary and justified. It raised the positive real rate of interest, naturally increased the EUR-HUF interest rate difference and pushed to appreciate the real effective exchange rate of the HUF. This monetary policy focused its activities on reaching immediate price stability and restoring MNB's own short-term credibility just for the sake of doing so. In fact, such a monetary policy was capable of slowing down the unrealistic rise in domestic currency denominated (loan) demand only selectively and with a low efficiency at the best. The appreciation of the real effective exchange rate (the "strong HUF" of the weak economy, which was impossible to sustain in the light of the high external imbalance as well) got detached from the difference in the growth of productivity (improvement in competitiveness) compared to our major markets. The difference between interest rates for the HUF and for FX was very high, 5-6 percentage points on average (which the MNB immediately increased even further - thereby granting an implicit exchange rate hedge for FX debtors whenever the HUF exchange rate got weaker). The positive real interest rate level, which was also high compared to the expected inflation, in itself contributed to making the extremely deep macroeconomic adjustment only half-successful. This was primarily because it applied the brake and fostered the growth where 
it should not have. It "succeeded" in slowing exports and encouraging imports. At the same time, it held back small and medium-sized enterprises, restricted job creation, continued to boost mainly retail (mortgage and consumer loan) demand, and mitigated domestic financial savings. Along the way, it "successfully" and unreasonably raised the price of financing government debt denominated in HUF (thereby transferring significant income to non-resident investors), and as the balance of all the above, it had an adverse impact on external balance while making the country more unilaterally dependent on global capital markets. Overall, the restriction on demand remained unsuccessful on the monetary side, and the fast credit expansion uninterruptedly continued. Between 2004 and 2008 , the volume of loans increased by $20 \%$ p.a. on average, and within that, FX-denominated loans rose by $30 \%$ per year, making up $60 \%$ of the total loan portfolio. In contrast with the direction taken by fiscal policy, monetary policy remained expansive.

And yet, MNB apparently did what was proposed by most textbooks and international financial institutions, particularly in continental Europe: if and as long as inflation remains stubbornly over the targeted rate, and inflationary expectations do not ease, there is no choice but to tighten monetary conditions. Raising the interest rates will slow down credit growth, encourage financial savings and appreciate the exchange rate. If credible, this will decelerate demand, reduce inflationary expectations and inflation. What happened in reality was something completely different. In a small open economy with a completely liberalised capital account, one should have proceeded with special care:

1) Monetary policy is not omnipotent. If external shocks, such as fluctuations in world market price, the fiscal/tax and income policy specifically, weather effects (this one might be less restrictive but is not insignificant as regards food prices) generate a significant imbalance, monetary policy cannot successfully fulfil its most important task. Typically, a permanent and sustainable equilibrium and, as a result, the anchoring of inflationary expectations around price stability can be achieved for the long run typically with close coordination between fiscal policy, income policy and monetary policy in a small open economy with favourable processes in the world market and with terms of trade that do not deteriorate substantially. The monetary authority in itself is insufficient for this.

2) Excessive austerity in monetary conditions is clearly counterproductive. On the one hand, the interest rate increase really slows down the increase in HUF loans and appreciates the exchange rate, thereby easing inflationary pressure. At the same time, the growing difference between HUF and FX interest rates and the appreciation in nominal and real exchange rates make forex lending increasingly attractive, but bring a boom in demand that renders the high rate of inflation permanent. 
3) Excess demand for forex loans, its impact of strengthening inflation and the appreciation of the exchange rate obviously deteriorate external balance. This also renders high inflationary expectations permanent through a quick growth in external indebtedness. A situation arises in which the central bank steps on the accelerator rather than the brake, in spite of its intentions. The central bank has said many times that the appreciation of the HUF in real terms was a natural phenomenon accompanying the realignment process experienced in the region. The Czech and the Slovak Crown or Poland's Zloty have indeed appreciated considerably. In these countries, however, this reflected the productivity surplus and improvement in competitiveness compared to their major markets, rather than the enormous interest rate difference. (While the difference was typically 5-6 percentage points in Hungary, it was negative in the Czech Republic, $1 \%$ in Slovakia and $2-2.5 \%$ in Poland.) This is substantiated by the fact that the appreciation of the exchange rate in real terms was not coupled with an outstanding rate of international indebtedness in those countries.

4) It was MNB's new management that proposed to abolish the last derogation concerning FX transactions between residents in the summer of 2001, in complete agreement with international organisations and in line with the orthodox approach prevalent before the crisis. I myself have always insisted on maintaining this derogation earlier. Without it, the room for running monetary policy efficiently is extremely reduced. In this case, for instance, the outcome is monetary easing instead of tightening and a deterioration of the balances and definitely missed the inflation target. This is particularly the case where, unlike the Serbian, Croatian or Romanian central bank, MNB does not consider it as a task to influence the growth of the loan portfolio. This could have been restrained by a quantitative restriction (requirement of setting a lending ceiling and/or separate capital requirement for forex loans in cooperation with the Supervisory Authority), which was less fashionable and contradicted the orthodox approach that prevailed.

5) Since the MNB thought that both the quick increase in the loan portfolio and the increase in external indebtedness are natural market processes, the bank has not even attempted to influence it.

\section{WRONG POLICY MIX}

The faulty and inconsistent economic policy mix that was implemented, which did not reflect the intentions of the decision-makers, was sufficient for a serious reduction of budget deficit. This in itself is not an achievement to be downplayed. However, it was not sufficient for keeping all of the aggregate demand, and within that, primarily the demand for retail loans at bay, to encourage domestic financial 
savings and business investments, to improve Hungary's capability of external financing, to substantially mitigate external indebtedness, to develop the longterm sustainable conditions for growth, and in other words, to restore credibility. Therefore, despite the great sacrifices, the adjustment between 2006 and 2008 did no more than defend the country from a severe financial crisis (in spite of the external environment that was not unfavourable overall). Of course, this in itself was no mean feat, but even with the best of intentions it can only be regarded as a partial success.

It was in this situation that Hungary faced the deepening and broadening crisis of financial markets in the autumn of 2008. The crisis brought about a shock in real economy and an unprecedented liquidity. The sudden collapse of export markets and the nearly complete stop in the influx of external capital shook the foundations of Hungarian economy as well as of all Central European countries, giving a rough shake to the growth model considered to be sustainable until then. The growth model driven by export and investments relied significantly on the influx of foreign capital everywhere, although to varied extent. Growth was based on large deficits of the current account of the balance of payments, which were often unsustainable (up to two or three times higher than the Hungarian figure). In the liquidity crisis that evolved in the wake of the collapse of Lehman, in addition to a temporary halt in net capital influx (except for the capital involved from owners of large banks in foreign ownership), dried up liquidity in the forex market threatened the rollover of maturing financial instruments, or at least it became significantly more expensive due to the rise in country risk premiums. This was not something unique for Hungary. The severe liquidity squeeze (just as the real economy shock) struck all countries in the regions.

\section{WHY HUNGARY?}

Given that external resources waned for all countries and international money and capital markets froze, why was Hungary among the first countries to be forced to apply for external loans? The customary answer from both international experts (IMF, World Bank, analysts, etc.) and Hungarian authorities runs like this: Hungary was more susceptible to the liquidity crisis and was forced to avail itself of external help because the level of government debt and the portfolio of so-called uncollateralised FX loans were very high.

This explanation is clear, simple and easy to understand. The only glitch in it is that it is not convincing and is no more than a half-truth at best. A successful economic policy response to the crisis would obviously have demanded efficient handling of the reasons that provoked the crisis. If crisis management is 
successful, it should have caused a visible drop in the volume of government debt and FX loans, and as a result the performance and market sentiment on Hungarian economy should have improved. Doubtlessly, market opinion and the assessment of the experts mentioned above of crisis management became more favourable after mid-2009. This occurred in spite of the fact that from $66 \%$ public debt rose to nearly $80 \%$ of GDP by the end of 2009. Though the portfolio of FX loans decreased slightly, the rate was about similar to the drop in HUF loans. Thus, one of the reasons that allegedly transformed the crisis into one that was particularly dangerous for us became even worse, while the other barely changed. This gives reason to question the causal relationship, as the allegation would fail even the simplest test of formal logic.

Though it is true that Hungarian public debt remains markedly higher than that of the other countries in the region (which, of course, is not favourable at all), but is still lower than the average of the Eurozone member states. It is also a fact that the volume of FX loans was high but not unique in the Central and Eastern European region. However, the external imbalance amassed over the decades and, in particular, after the significant improvement between 1995 and 2001, caused and causes a much deeper vulnerability. The total external indebtedness accumulated in foreign currency jumped from $40 \%$ in 2001 to nearly $100 \%$ by 2008 , rising to over $120 \%$ after drawing down the EU - IMF loan.

For all economic policies, the real threat and real barrier is a high external imbalance, that is, great dependence on foreign savings, international money and capital markets. The underlying reasons, of course, by necessity and particularly in the period before 2006, are the current account and budget deficits (twin-deficit) that were significantly higher than sustainable and/or the rate of net financial savings of households which constantly remained well below the necessary rate. This means that the unsuccessful external consolidation after 2006 was due to a fiscal adjustment implemented with an unfavourable structure, and a monetary policy that continued to encourage domestic private and, within that, primarily household FX borrowing loan demand while dampening net financial savings of households. This economic policy mix offered no break from the trap of slow growth, quick increase in foreign indebtedness and the rise in government debt compared to GDP even on a longer time horizon. Therefore, instead of the high level of indebtedness (i.e. stock of debt) by domestic income holders and, especially, the composition of this indebtedness by currency, most of the burden of guilt lies in the intensive external indebtedness that went on unsustainably until 2009. This was what needed to stop at all cost.

What should have been reigned in was the loss of balance between macrolevel savings and investments and hence the current account deficit. However, neither Hungarian decision makers nor international institutions paid any heed 
to this. They focused frantically only on the budget, as though the indebtedness of the private sector did not represent an equivalent burden on external accounts, thereby threatening the sustainable course of business. It means that the current account deficit should have been brought down to a sustainable level.

However, this would have already called for a fundamentally different economic policy mix before the crisis. Following the cut in budget deficit, it was not the relatively high level of government debt but the low rate of net financial savings by households and the unruly retail borrowing that maintained the Hungarian economy's great need for external financing. Therefore, the main threat was not the high volume of FX loans in itself and in particular, but the unsustainably high growth in the combined loan portfolio, i.e. HUF and FX loans, for years (with a rate over $20 \%$ per year on average), and the low level of financial savings of households. ${ }^{2}$

Neither the relatively high level of government debt nor the high portfolio of (forex) loans, and not even the relatively significant external indebtedness offers a full explanation to why Hungary was among the first to apply for a loan to international financial institutions. It is true that the drying up of international money and capital markets may perceptibly be even more dangerous when a country's government debt is higher; it has greater demand for current financing (budget deficit and the need to roll over maturing government debt) and has a substantial volume of forex loan refinancing. In the autumn of 2008, the pressure on Hungary was further aggravated by the fact that all market operators had considerably less trust in Hungary due to the economic policy of earlier years, compared to the other countries of the region.

\section{ILLUSIONS INSTEAD OF RESERVES}

However, when markets freeze and channels of external financing block up, the billions of euro a country is unable to repay, then the number in billions barely makes any difference. In several other countries of the region, where access to external markets was blocked just the same and liquidity was removed just the same if not to a greater extent, there was no immediate need to resort to external help. The basic explanation to this is that the central banks of the region's other

2 The economic policy of the period before 2008 failed to return to the growth path driven by export and investments in spite of the relatively favourable external economic conditions after the 2006 adjustment, and continued to actually foster domestic demand and specifically housing related investments. Some interpreted this as smoothening out household consumption in a debatable manner in this instance. 
countries had sufficient international reserves to bridge a few months. In sharp contrast, the level of MNB's foreign-exchange reserves was critically low in comparison to not only Hungary's external indebtedness, but even to the level of imports. In this respect, Hungary was indeed the Central European region's most vulnerable economy in the autumn of 2008. The central bank's reserves amounted to EUR 16.3 billion. The Czech Republic, the size and openness of which is similar to those of Hungary while its external debt was about half of ours, had EUR 27 billion of reserves when the crisis broke out. This level of reserves was triple that of ours on a pro rata basis. One might cite the examples of Slovakia, Croatia, Serbia or even Poland as well.

For a long time, MNB harboured the illusion that there was no need for significant foreign-exchange reserves. It believed that the clean and "holy" market would resolve all imbalances through the automatism of supply and demand. This is true, although with some limitations. Through the mechanism of supply and demand the market develops some kind of balance somewhere in any situation ex post. The only question is the extent of depreciation or appreciation at which it takes place. The explanation that MNB has not emphasised officially, according to which the international reserve requirement analysed with the Guidotti - Greenspan indicator implied a significant shortage of reserves only a few months before the crisis unfolded, is not convincing as an argument. The severe lack of reserves should have become obvious for decision makers by simply taking a look at the neighbouring countries, or following one of the best-known rules of thumb, the level of foreign-exchange reserves measured as a ratio of imports. In terms of imports, the level of the central bank's foreign-exchange reserves decreased to 2.4 months, and obviously, imports did not increase overnight. The internationally accepted minimum level of reserves that is required not to threaten solvency is three months for countries with non-liberalised, nonconvertible foreign exchange regime. However, Hungary is a country with a fully liberalised current and capital account, so it should have had substantially higher reserves. ${ }^{3}$ One year later, Hungary's foreign-exchange reserves exceeded EUR 30 billion (about 5 months' imports). If anything, this factor really showed a fundamental improvement accompanying with improvement in external balance as well. Therefore, by 2009, Hungary's vulnerability was indeed greatly reduced due to the rise in foreign exchange reserves, although even this might have been insufficient.

3 It had reserves 15\% less than the minimum reserve level calculated on the basis of the Guidotti - Greenspan indicator, expressed as a ratio of GDP, cca. EUR 5 billion less, already in 2007. 


\section{THE MAIN REASON FOR APPLYING FOR A LOAN}

Simplified somewhat, the loan taken out from international institutions was used to fill up foreign exchange reserves (meaning it barely represented any direct substantial easing for the real economy). This in itself significantly raised Hungary's gross foreign indebtedness, leaving net debt unchanged, which was an important factor. The failure to fill up foreign exchange reserves, while market liquidity was unprecedentedly high, imposed a fundamental restriction on the response that could be given to the crisis by monetary policy. In summary, therefore, all weaknesses of the Hungarian economy, such as the relatively high level of external indebtedness, the significant rate of government debt, the overly extensive government redistribution in a bad structure, the extremely dynamic increase in HUF and FX loans in an unfavourable structure rather than the level and forex structure of the latter, the significant overvaluation of the HUF, the high positive real interest rate, and, not least, the severe decline in the potential economic growth rate due to a combination of these factors - still fail to fully explain the pandemonium in the autumn of 2008. Unlike in the other countries of the region, the urgent call for external help by the government and the central bank was predominantly prompted by the critically low level of foreign exchange reserves.

The responses given to the crisis by Hungarian economic policy can be understood only from this position (though they may or may not be agreed with). For this once, it is worthwhile to start the analysis from the side of monetary policy. Naturally, markets had a full and clear understanding of the Hungarian economy's (external) vulnerability following the Lehman bankruptcy. In the absence of ample foreign exchange reserves, the Hungarian money and capital markets, including the artificially appreciated HUF, became an easy target of market speculation. With no sufficient international reserves, MNB was disarmed, unilaterally vulnerable to markets, watched things unfold and was unable to make any substantial market intervention on its own resources. It closely watched as the exchange rate of the HUF was dangerously depreciated, market interest rates and risk premiums jump-started, the market of government securities dried up for the second time in a year, and the lack of liquidity in the banking system became increasingly depressing in both forex and HUF.

The central bank, which has argued in favour of the "strong" HUF of a weak economy (claiming the exchange rate had no impact on exports - sic!) contemplated the HUF's downfall numbed for quite a few days. Afterwards, it was the only central bank in the region to dramatically raise the prevailing interest rate by 300 basis points, this time with good reason. However, the questions arise again: 
- why did it fail to also intervene on the FX market?

- why did it fail to offer generous liquidity support to the banking system in HUF and in FX? and

- why did it fail to enter the secondary market of government securities (open market operations or QE) by generating liquidity?

There were probably two reasons for all these. One is the reason of technical nature mentioned earlier, namely, the lack of adequate foreign exchange reserves (as the old adage goes, when a village was reprimanded for not having tolled the bell to greet the king when he came around, the village leaders said there were a thousand reasons for not tolling the bell, the first being that there was no bell). The other is a broader principal consideration, which may have contributed to the emergence of the shortage of reserves.

MNB refused to even consider any kind of intervention in the FX market for reasons of principle in August-September of 2008 as well. Needless to say, nobody believes that the basic processes determined by the fundamental factors could have been permanently reversed by intervention. ${ }^{4}$ Yet, intervention, buying and selling foreign exchange in the market is a fundamental instrument of monetary policy for influencing market liquidity. It is no coincidence that it forms part of the monetary policy toolset of all serious central banks (except for the MNB before January 2009). The central bank in itself is capable of curbing, reigning in, deter or at least not lean into market speculation somewhat if it has reserves of an adequate level that are easy to mobilise. Or, by moving in the opposite direction, for instance in the years before September 2008, it could have filled up foreign exchange reserves to the necessary extent under peaceful circumstances; by avoiding an unrealistic appreciation of the HUF (provided it did not concentrate on the single dimension of suppressing inflation with all its strength). Naturally, this costs money, and no little money at that point (and could have resulted in slightly higher inflation which, in exchange, would have been sustainable and, therefore, credible), but it still costs less than the damage caused by a monetary policy paralysed by the lack of reserves. All insurance costs money in the world, and as long as there is nothing happening, the insurance premium might seem to be money out of the window.

4 Obviously, the market sentiment and expectations may get significantly detached from the fundamentals in short periods, so that market processes may differ from them. However, market sentiment may be influenced by adequate communication, verbal intervention and adequate reserves. The market is not always right, either. For instance, we were able to avoid a depreciation of the HUF by massive forex market intervention and some implicit interest rates increase at the time of the Russian financial crisis. 
In the absence of sufficient reserves, it is not just about having had to resort to the IMF for a loan and to fill up reserves right away in October 2008. The low international reserves prevented the central bank from fulfilling one of its fundamental functions. The central bank was unable to ensure smooth liquidity in the Hungarian financial system even in the short term, on a time horizon of three to six months, meaning it was unable to function as lender of last resort only in part.

\section{WHAT THE CENTRAL BANK COULD NOT DO}

The central bank failed to ensure quick and generous HUF liquidity at a sufficient extent, given the depth of the crisis and the drying up of liquidity, either in FX or HUF. The possibility for spillover is essentially unlimited, basically because there is no Chinese wall between HUF and foreign exchange in a framework of complete convertibility. ${ }^{5}$ In the situation that emerged, a generous provision of HUF liquidity along with the collapsing domestic demand would have threatened Hungary's solvency directly rather than primarily the inflationary target.

In addition to the technical restriction caused by the lack of reserves, there were serious principal considerations leading MNB to be much less prepared for the crisis than its peer institutions abroad. Over the years before the crisis, MNB was perhaps the only one to put blind faith in the unrestricted self-regulating capacities of financial markets and in their efficiency. It adopted the role of the observer and sternly rejected all behaviours to the contrary. Prior to the crisis, the bank unilaterally discarded the possibility of intervention on the FX markets ${ }^{6}$ as well as the quotes for FX swaps (i.e. exchanging forex deposits to HUF deposits) and through that any influence on liquidity just as open market operations and actively shaping market liquidity and market expectations.

Of course, I can almost hear the central bank’s answer: "After the crisis broke out, in addition to raising the interest rate, we extended the range of securities that can be discounted by banks, quickly introduced overnight forex swaps, and later on, the 3-to-6-months FX swap, we entered the secondary market for government securities, and have carried out interventions on FX markets after January

5 Which is why I consider the sharp distinction made between financial instruments denominated in HUF and in foreign exchange to be overly simplistic; according to this distinction, the HUF is quasi-safe while FX is too risky for both individuals and the macroeconomic level.

6 See the strengthening of the HUF exchange rate to 228 HUF/EUR in the spring of 2008. In May 2008, citing highly debatable arguments and earning IMF's blessing, it had the really comfortable $+/-15 \%$ exchange rate band abolished. Afterwards, it raised the interest rate, as a result of which the HUF, already harmfully appreciated, strengthened from 239 HUF/EUR to $228 \mathrm{HUF} / \mathrm{EUR}$. 
2009." While this is all true, the problem is that to save for the overnight swap, the central bank has implemented all of its steps with a significant delay, with restrictive and/or unrealistically overpriced, sometimes downright impossible conditions and usually at a low efficiency due to the insufficient quantity. It acted half-heartedly, as it remained captive to its own ultra-orthodox attitude all along. It always believed that the central bank of even a small open economy is capable of creating price stability independently from external and internal processes - all it needs is a will. Following the agreement reached with the IMF, the primary obstacle to MNB's proactive, brave and innovative conduct using a broad range of non-conventional methods with ample flexibility had to step over its own shadow, rather than technical restrictions.

First and foremost, it needed to make a fundamental change to the principles underlying its attitude, which has occurred worldwide in the wake of the crisis, but failed to take place here in Hungary. Second, instead of rephrasing its own opportunities, it specified the way to lead out of a crisis involving primarily liquidity, in unilateral restrictions on fiscal policy, which was a highly debatable choice.

That is, no fundamental reconsideration of the monetary policy framework took place even given the information available on the prospective significant increase in liquidity promised by international financial institutions. Instead, the central bank urged for further fiscal austerity, which escalated the otherwise grave effects of the crisis. Unfortunately, the government in office adopted this mistaken approach as well. In contrast with news to the contrary, further fiscal austerity was not pushed by the IMF. In the first step, a deficit cut in excess of the original convergence programme supported by Brussels was targeted, first from $3.4 \%$ to $2.9 \%$ then to $2.6 \%$. With the GDP that could be foreseen to shrink considerably, the central bank demanded an even stronger pro-cyclical fiscal policy to an unreasonable extent, instead of at least a neutral if not anti-cyclical policy. When the government and the central bank joined forces to push for a reduction of public deficit to $2.6 \%$, the expected drop in GDP was estimated at already $3-4 \%$ for 2009. Unfortunately, the programme failed to take into account that a pro-cyclical budget as planned would cause GDP to fall even further than the rate estimated until then. Therefore, instead of the correct target of halving the external imbalance (from $8 \%$ to $4 \%$ of GDP) it was able to swing to a position at least close to the balance. ${ }^{7}$

Similarly to other economies in the region, the Hungarian economy faced several extremely strong shocks in the autumn of 2008. The first immediate shock

With a 3-4\% drop in GDP, a $0.8 \%$ reduction of annual public deficit - from 3.4\% to $2.6 \%$ represents an even higher further reduction of demand corresponding to 2-3\% of GDP after adjusting it for the cycle. 
in real economy was caused by external demand, the $20 \%$ collapse of export markets. Second, the entire economy was shaken by the shrinking of forex and HUF liquidity. Monetary policy was able to respond to these shocks only with a delay and inefficiently, due to the reasons of principle and practice. And in the meantime, fiscal policy ran out of opportunities as well.

It is unquestionable that Hungary lost the opportunities for an actively anticyclical fiscal policy that would have actively increased deficit during the crisis much earlier, in the years before the crisis. As a consequence of the severely irresponsible economic policies, primarily fiscal and income policies of prior years, fiscal policy was not or just barely able to counter the blows of the crisis, in contrast with the neighbouring countries. The fact that the first sudden response of the government and the central bank was to keep further reducing the deficit (which was a mistake) was a consequence of the false diagnosis. Outside the countries with the key currencies, financing the budget caused temporary difficulties in other countries as well due to the general drying up of international and domestic money and capital markets. In those countries, however, the central banks took firm and confident actions, often resorting to unorthodox/unconventional means, making them perceptibly capable of dampening the tensions in market financing, including government securities. A condition necessary but not sufficient for doing so was that these central banks possessed foreign-exchange reserves that offered sufficient buffer in the short run for countering the shrinking of domestic foreign exchange supply, making up for a part of the forex influx lost, and for satisfying payment obligations and conversion needs. In other words, they were able to avoid a free fall in the exchange rate and a dramatic jump in prevailing interest rates. They were able to buy time. This is why these countries were forced to apply for external help much later. However, early in 2009, it was clear for everyone that all countries with non-key currencies would need some external, international support sooner or later as the liquidity crisis grew longer. Poland is a very good example for this. The government of Poland, which suffered the smallest injuries during the crisis, was forced to resort to the IMF in the spring of 2009. Poland proposed to use USD 20 billion of the credit line set up for stable economies, available for drawing down automatically with no special conditionality.

\section{WHAT THE CENTRAL BANK DID NOT DO}

In these countries, therefore - even if central banks did not wish to and/or could not prevent a drop in the exchange rate of the national currency - there was no threat of a total collapse of foreign exchange rates and/or the banking system, or of insolvency. In contrast, domestically the stop in the influx of foreign capi- 
tal, the massive sales of government securities by non-residents (withdrawal of capital) outlined a threat of sovereign insolvency and illiquidity of certain banks, given the absence of sufficient international reserves.

Without immediate and generous liquidity provided by international financial institutions, MNB was indeed unable to propose a large-scale monetary easing. In contrast, it had to bring austerity by raising interest rates. This in itself was a problem, which aggravated the crisis. Seeing the central bank's passivity, the Hungarian banks learned that they were able to resort to the central bank on a highly selective and restrictive basis even in the emergency situations. They learned how little the central bank was able to fulfil the function of lender of last resort. Essentially, they could only count on their parent banks to help with liquidity, some of which struggled from very substantial problems in themselves. Therefore, the Hungarian banks stepped on the brake in lending, sealed off from the markets, taking immediate action, and in a sense sealing their own fate because they could rely on the central bank to an extent that was smaller than needed. In doing so, they carried out one of the deepest credit squeezes in the region, which further worsened growth prospects of the economy. ${ }^{8}$ Therefore, it was not possible to carry out general and quick monetary easing even with the IMF agreement, as international markets closed down and country risk premiums became stratospheric. A substantially looser monetary policy would have undermined the exchange rate of the HUF, unleashing inflation and inflationary expectations.

However, in January 2009, the central bank emitted signals and made decisions that implied a dangerous general easing in monetary policy. ${ }^{9}$ The unfortunate communication concerning the exchange rate level early in the year and the further reduction of interest rates by the central bank, a mistake at the time, suggested that the central bank's policies were moving from one extreme preference to the other, forcing a strong HUF for a weak HUF. By reason of the exceptional and atypical coincidence of events, the great drop in energy, raw material and food prices and the rupture in domestic and foreign demand temporarily countered the inflationary effect of the dangerous depreciation of the HUF, which as

8 Of course, the Hungarian banks are far for being innocent as regards the emergence of the boom in lending and the steep decline in portfolio quality that followed suit. For instance, bank vulnerability would have been perceptibly mitigated by applying much lower/stricter maturity mismatch, requiring much higher own resources, a lower loan-to-deposit ratio, stricter debtor rating, smaller volumes of short-term forex lending for consumption purposes, the excessive mismatch between forex funds and their placements as regards maturity, and an agreement to lend only in EUR if at all. A detailed analysis of these factors is beyond the scope of this article, similarly to the evaluation of the Supervisory Authority's role.

9 In addition to the uncertainty in global economy and domestic policy, this is likely to have contributed to the emergence of a HUF/EUR exchange rate of over 300 HUF. 
much as exceeded $300 \mathrm{HUF} / \mathrm{EUR}$, and this effect is usually quite strong. Under normal circumstances, a depreciation of as much as $25 \%$ would have entailed an immediate acceleration of inflation and severe deterioration of medium-term inflationary expectations. Due to the global crisis and the price drops that inevitably accompanied it, the collapse of the exchange rate would have crushed "only" a few hundred thousands of families and the entire banking system at that point, in the initial round. However, with a slight delay, inflation would also have run free in the second round.

Instead of a general and unfounded easing of monetary policy, it would have been possible to give significant assistance to mitigate the decline in real economy in a targeted manner and in coordination with fiscal policy. The formula is quite simple. The shock in external demand led to a collapse in exports. The fiscal shock coupled with the monetary shock created a dramatic decline in domestic demand without exaggeration. The latter means that demand for both investment and consumption collapsed along with production. Consequently, it was already clear early in 2009 that the external balance would be substantially better than under the approved programme. And indeed, instead of the targeted and sustainable deficit of $4 \%$ in the current account of the balance of payment, there was a surplus of about $2 \%$ in 2009 , unseen for decades. Therefore, barely credibly, the external balance improved by nearly $10 \%$ of GDP over the course of a year.

However, this gave no reason for unbounded joy. The turnaround was caused by the total collapse of internal demand and excessive cooling of the economy, and not by a boost in exports; this was not 1995 . Paradoxically, with such a shrinking economic performance, the better the external balance is, the worse the budget balance would be. The spectacular improvement in external balance in excess of the desired rate is fed by the collapse of production, investment and consumption. The collapse of domestic demand, the shrinking of production, consumption and investment and the rise in unemployment prompt a decrease in government tax revenue in excess of plans and, primarily, a rise in social expenditure.

Thus, it became clear that an external balance that is substantially better than planned would have entailed a substantially higher drop in GDP and a substantially greater budget deficit than originally targeted. Therefore, the target deficit for public finances was gradually increased from $2.6 \%$ to $3.9 \%$.

However, even in spite of increasing the deficit, the new government had to carry out a further dramatic cut in public expenditure and a tax increase in the middle of 2009, further strengthening the pro-cyclical nature of its policy amidst the deepening crisis. Essentially, the Hungarian economy entered a vicious cycle. Instead of raising the public deficit to about $4 \%$ right at the beginning of the crisis (as we have seen, the level of government debt was not the most vulnerable point), just the opposite took place. Even this would not have constituted budget- 
ary easing. To the contrary; it would have resulted in austerity coupled with the shrinking GDP. This was one of the reasons why the crisis and the contraction of the economy became greater than was inevitable (at $6.9 \%$ instead of $4-5 \%$ ). It became much more devastating, and the recovery started much later, while budget deficit and government debt turned out to be higher than originally envisaged.

Had monetary policy been somewhat bolder and more innovative, it could have helped internal demand, or, more precisely, could have attempted to dampen the decline in demand. Instead of using non-conventional means on a broad scale to expand liquidity in a targeted manner and especially to selectively encourage domestic private investment (in close cooperation with the budget) already at the dawn of the crisis, the central bank continued to look at (credit) market processes from afar. Just as it has idly watched the running away of loans in earlier years, the bank continued to watch the shrinking of the loan portfolio from a distance. Or, it set conditions for e.g. 3-to-6-month forex swaps that were barely possible to meet. However, the central bank "did even more". It did not simply assist in the narrowing of loan markets; it pursued a course of action to further restrict the supply of loans by proposing first an informal, then a formal limit on forex loans. The central bank boosted activities in places and at times it should not have, and imposed restrictions in places and at times it should not have. If anything, it should have prevented forex loans in currencies other than the EUR, in cooperation with the Supervisory Authority, right from the outset. Such currencies represented a double exchange rate risk. The variation in the CHF/EUR exchange rate is a risk that is actually and perfectly uncovered, because in contrast with the EUR/HUF exchange rate which fulfils the role of a nominal anchor, it has no impact on domestic nominal processes, i.e. inflation, interest rates and wages, even indirectly.

As a result of the crisis, the supply of FX loans was tremendously narrowed and made more expensive by itself, and demand for such loans decreased, quite understandably. On the other hand, there were no HUF sources available in the capital market for the medium and long term, and whatever there was, was absorbed by the budget (crowding out). This was also one of the reasons why it was not sufficient to scare market operators constantly by restricting forex loans, and to unilaterally restrict them on administrative grounds, ex post. I say this even though I would not have excluded doing so straight away. Implicitly, this might suggest that the central bank itself had no trust in the feasibility of price stability, accession to the Euro zone in the medium/long run, and in doing so, it would have contributed to stabilising the unfavourable expectations and interest risk premiums at a high level. By the way, there were no grounds for restricting only forex loans, because in the long run, it cannot be confirmed that unhedged forex loans (this applies only to reference currencies) have a higher risk than the risk 
of, for instance, variable/floating rate HUF loans (where here the interest rate is unhedged) in a small, open, catching up economy.

If anything should have been restricted in addition to CHF loans, it was the emergence of the dangerous, permanent and large deficit of the current account, and financing of this deficit out of external loans. If a country makes a living on loans, that is, the savings of other countries on a permanent basis, the balance between investments and savings is upset in the long run, and it is perfectly normal that some and/or all of the domestic income holders have uncovered forex positions. This is a simple equation in the balance sheet. The real question as always is the extent of this, rather than its distribution among domestic income holders. ${ }^{10}$

If the ratio of FX loans is really worth cutting down (and it is not necessary to limit the growth of total lending in general), a supply of HUF loans should have been created with sufficiently long maturities, available selectively for private investment purposes, with acceptably low interest rates (funding for lending). The financial intermediaries in the market were unable to do this by themselves, given the economic policy and, within that, fiscal and monetary policy environment prevailing at that time. Though the banking system's liquidity was completely restored by 2010, this stems primarily from the fact that with a bit of exaggeration lending came to a complete halt, in addition to the easing of the global crisis and improved assessment of Hungary. The banking system deposited its free liquidity consisting clearly of short-term deposits with the central bank. At macro level, the financial savings were available for promoting investments, which was reflected by the improvement in external balance, much higher surplus than desirable. These financial savings consisting of short-term individual funds or a part of them should have been transformed into long-term investment loans for small, medium-sized enterprises and large corporates as well as for households (for housing) at acceptable interest rates. That is, the external balance that was much more favourable than intended, tolerable and reasonable, was an inadvertent side effect of the economic process that went on along a downward spiral. Though the improvement in external economy gradually mitigated the vicious cycle of economic decline, it would have been reasonable to promote internal demand in a targeted manner and to dampen economic decline on a temporary basis with a view to the exceptional crisis situation for a couple of years. (This took place much later, only after 2013.) At that time, it was not possible to do by unilater-

10 Within certain limits, a government is able to manage open forex positions at much lower risks than households. However, at that time, the HUF financing for the budget was exclusively pushed unilaterally and unreasonably, in accordance with the doctrine prevailing at the time, reaching an almost complete crowding out for the private sector. 
ally deteriorating the fiscal balance on a considerable scale. In contrast, it was possible and would have been necessary to attempt to mitigate economic decline and the increase in unemployment by taking targeted action with the participation of the central bank and the budget, promoting mainly private investments rather than consumption.

Finally, it may be possible to draw the conclusion that in 2009, it was no coincidence that the Hungarian economy was the only one to detach itself from the general trend prevalent in the region. In contrast with the neighbouring countries (this time including Austria, Germany and Italy as well), Hungary was the only country where the growth figure remained negative in the third and fourth quarters. It is hardly a consolation that growth was not robust in other countries either, but at least they have shifted from the bottom. The decent efforts of the Bajnai administration ${ }^{11}$ and the adjustment to the budget have undoubtedly pulled Hungary back from the brink of the abyss. However, the Hungarian economic policy continued to rely on a mix of fiscal and monetary policy with an incorrect structure. The inevitable austerity of fiscal policy manifested itself where it should not have (e.g. the abolishing of the welfare subsidy in the housing market), or eased where there was reason for the opposite (such as abolishing the fixed-amount health care contribution). As regards principles, monetary policy showed a consistent continuity with earlier years, as a welcome exception in exchange rate policy after some mishaps. The monetary authority failed to even analyse the possibility of how the crisis of the real economy could have been moderated by renewing monetary policy instruments in a particularly severe situation. ${ }^{12}$ Finally in spite of the continued orthodox and unilateral efforts, the MNB failed to come closer to its' inflation target.

Fiscal consolidation, which was successful in quantitative terms, failed to create the conditions for growth, higher employment and better living conditions, and barely improved the Hungarian economy's low growth potential. It would have been absolutely necessary to reconsider fiscal and monetary policy, to fundamentally restructure the economic policy mix in order to stop the historical lag behind and the social disintegration of the country.

11 Mr. Gordon Bajnai was Hungary’s Prime Minister between April 14, 2009 and May 29, 2010.

12 Let alone the fact that the central bank further aggravated the burdens of the crisis, which were already high enough, by filling up reserves only in EUR, given the escalation of the Eurozone crisis in 2008-2009, and by rejecting the conversion of forex loans into HUF loans early in 2011. 